\title{
10. Journalism and HRECs: From square pegs to squeaky wheels
}

\section{ABSIRACI}

This article follows on from a discussion by Richards (2010) about ethics committees and journalism researchers being 'uneasy bedfellows'. It argues that there is scope for research using journalism as a methodology to be approved by Human Research Ethics Committees (HRECs), while acknowledging that work needs to be done in familiarising journalism academics with the National Statement on Ethical Conduct in Human Research (2007) and HRECs with journalism as a research methodology. The issues that arise as journalism academics and HRECs meet tend to focus on the requirement of informed consent and timing problems, but these are not insurmountable and there are clauses in Australia's National Statement that provide scope for exemptions from these requirements. This article includes input from an interview with Professor Colin Thomson, one of the members of the NHMRC/ARC/UA working party that drafted the 2007 revision of the National Statement, clarifying the intentions of the authors with regard to Fourth Estate research, by journalists, as well as by researchers from the fields of business, law and politics. It also highlights the points of contention and common confusions that frequently arise and suggests ways that journalism academics can act collaboratively to change the current status quo.

Keywords: censorship, ethics, informed consent, journalism ethics, research methodologies

KAYT DAVIES

Edith Cowan University, Perth

M ANY OF the journalists employed by Australian universities to teach undergraduate journalism are employed as research academics, expected to both teach and produce research. While most of them are skilled in the use of journalism as a research methodology very few 
of them use it for their university research work. This is the result of a series of events and arguments over the past 30 years that have shaped the work done by contemporary journalism academics. This article will not recap that history because that work has already been done by scholars such as Bacon (2006) and Bromley (2006). Instead, this article calls for change, the commencement of a new era of research journalism, and it tackles the oft-raised obstacle of difficulties getting journalism projects approved in a timely manner by HRECs. This approval is an issue because, while compliance levels vary all Australian and New Zealand universities require that all research conducted by academics that involves human participants be approved by in-house HRECs, or by approval bodies subsidiary to university level HRECs. The lever that compels universities to impose this requirement on their researchers is that it is an eligibility pre-requisite for access to public funding via the National Health and Medical Research Council (NHMRC), and the Australian Research Council (ARC). The composition and role of these committees is prescribed by the National Statement on Ethical Conduct in Human Research (National Statement), which was jointly developed by the NHMRC, the ARC and the Australian Vice-Chancellors' Committee (AVCC). While this article will focus on the current Australian dynamics many of the principals discussed are also relevant to New Zealand, which has a different, yet broadly similar, system operated under the auspices of the Ministry of Health.

The most compelling argument for motivating, or liberating, journalism academics to use journalism as a research methodology with which to study the world is that commercial media is facing a financial crisis that is affecting the quality of the journalism being produced and published (Davies, 2008; Rosen, 2008; Tiffen, 2009). Journalism academics could be stepping into the breach to a greater extent and providing balanced coverage of matters of civic and social importance. By peer reviewing each others' journalism they could also be providing a body of work with a benchmark standard of integrity and quality that would highlight deficiencies in underfunded commercial journalism, and perhaps inspire greater investment in good journalism by media companies. And by documenting their processes they could be collaboratively building a comprehensive description of contemporary best-practice journalism.

What holds Australian journalism academics back from spending more time doing large scale journalism projects are problems with getting journalism 
to 'count' as research within the university system. 'Counting', in this context, means contributing to their allocated workloads. Most full time employed journalism academics are required to do one or two pieces of research a year and in most cases, in-house 'research auditing systems' require research work to be produced and published in a manner that will allow it to contribute to the university's tally of research for submission to the Australian Research Council's Excellence in Research Australia (ERA) research management initiative, or Performance Based Research Fund (PBRF) in the case of New Zealand. This is a canny financial move on the part of universities that are aware that the Federal Minister for Tertiary Education, Senator Chris Evans (2010), has said that ERA performance will influence future federal funding decisions. For journalism academics, however, it means stepping into a field of contention where the familiar act of using a best-practice journalistic approach to unearth or create some new knowledge or insights becomes mired in arguments about definitions of research and compliance with HREC requirements.

While these two issues should be thought of separately they are sometimes confounded. Although it is reasonable for a university to say that if a piece of journalism is being presented as a piece of research then it should have HREC approval, it does not follow that lack of HREC ethics approval means the work was not research. HRECs exist to judge whether research protocols are ethical or not, and not whether a proposal qualifies as 'research'. There is a definition of research in the National Statement that can be used to determine whether a project is or is not 'research', but a project's status as research or not research is not dependent upon it being deemed ethical by a committee - otherwise it would be possible for bad research to be approved.

Because the National Statement was drafted in a tradition informed by a medical research paradigm (Cordner \& Thomson, 2007) and because journalism is focused on questioning power, journalism (as a research methodology) is, by nature, a bit of a square peg to fit into the round holes of the HREC system. But thanks to the good work that went into the 2007 review of the National Statement, it is possible to get approval to do qualitative research designed to question people in positions of power. It may take time and patience however to learn which clauses allow this to happen and to ensure that HREC members are familiar with them and the intent behind their inclusion in the National Statement during the 2007 review process. 


\section{The National Statement genealogy}

The National Statement was first released in 1999, in accordance with instructions for its development embedded in the National Health and Medical Research Council Act 1992 (NHMRC Act). In 2007 it was reviewed and extended 'in response to requests for clearer guidance for those conducting research and those involved in its ethical review' (NHMRC, 2007, p. 3). Those requests included concerns raised by ANU Professor Robert Cribb, on behalf of the Australian Academy of the Humanities, and from politics academic Professor Anthony Langlois that prompted deliberation on how the National Statement could be amended to allow the interrogation of power, including interviews with people such as corrupt politicians and business people who are unlikely to verbally consent to being part of a research project and less likely to be willing to sign a consent form. Cribb and Langlois raised issues about the balance that needs to be achieved between protecting the rights of individuals, which is paramount in medical research and the beneficence of, or good done by, allowing academics to have a fourth estate function that safeguards the populace and civil society.

Changes incorporated in the 2007 review include the introduction of greater flexibility, and the revision of content aimed at making the process more responsive to the needs of different domains of research (Cordner \& Thomson, 2007). The 2007 review was conducted by the Australian Health Ethics Committee (AHEC), a principal committee of the NHMRC. A working party was appointed whose members included members of AHEC and representatives from the ARC and the AVCC. Colin Thomson, as the consultant in health ethics to the NHMRC, was also appointed. He is now a Professor at the University of Wollongong and Academic Leader for Health Law and Ethics in the university's Graduate School of Medicine. He also works as a consultant and has been involved in training HREC members in the use of the National Statement.

According to Thomson (personal communication,12 November 2010), deliberation on submissions by Cribb, Langlois and others resulted in the inclusion of clauses such as 2.2, 2.3 and 4.6.1-described in more detail in Davies (2010) - that allow for approval of mechanisms for acquiring proof of informed consent other than formal double signed letters and for the waiving of the requirement of informed consent altogether, if appropriate. The new clauses also allow for approval of projects that seek to expose corrupt and 
illegal behavior, which is clearly not in the best interest of the participant, if a greater social good results from the exposure.

The second common fallacy about definitions of research is the notion that where a piece of work is published determines whether or not it is research. With regard to journalism it is often said that work published in peer review journals is research, while work published in newspapers is professional practice. According to Thomson (personal communication, 2010):

Of itself, where something is published can't be a sufficient definition. Part of the academic tradition of research is that the reason we are doing it is, in simple terms, to generate new knowledge and that the work needs to be made available for some kind of peer/public scrutiny and so publication is commonly one indicia of research. But to rely on publication as part of the definition of research is putting the cart before the horse. The actual activity of the research and 'what is research that might lead to a publication' is something that is not defined by the publication.

Within a university context, raising the issue of problems with getting journalism approved by ethics committees provokes questions about what is special about journalism that it needs consideration in ways that other humanities research does not. While journalism as a research methodology has some features in common with the qualitative research methodologies used in other disciplines in the humanities, it also includes interrogative and opportunistic practices that make it unique, but not necessarily unethical or lacking in rigor (Lamble, 2006). The question also worries the journalism academics who took part in the heated debates of the 1990s now called 'The Media Wars'. These arguments saw them lobby hard and well to be considered equal alongside cultural studies academics, while others argued for journalism's peculiarity on the grounds that teaching journalism skills and cultural studies theory concurrently was confusing to undergraduates. The history of these arguments has been well documented by Turner (2000) and Bacon (2006) and others and it does not need to be retold here, other than to reiterate a Bromley line, cited by Bacon, stating that 'just because not all journalism is research, doesn't mean journalism can't be research'.

This begs the question: When is journalism research, and/or if it is not research what makes it not research? This is pertinent now that the usefulness 
of being deemed 'not research' and thereby able to sidestep HREC bureaucracy is waning because of the pressure on universities and academics to chalk up as many 'research outcomes' as possible.

Asked for comment, Thomson (personal communication, 2010) described this as 'a cutting edge question' and added that journalism

has been one of the pejorative terms that people have used about academic writing. To say 'this is merely journalism' or 'this is journalistic in style' is as much as to say this isn't academic discourse, this is merely collecting facts and reproducing them. I think that what you are seeking to say is that journalism as an academic discipline has a status that needs to be recognized in the same way that other disciplines, broadly in the social and humanities arena, are - and that is has its own research methodology. This is a shift from the way older people, like me, generally see it, as not a discipline but a practice that hasn't been part of academia. But I know that that's an ignorant thing to say because universities have had programs for a long time that have taught and trained journalists.

In saying this, he captures and critiques the argument that research that 'merely' collects and presents facts somehow falls outside the definition of research. Considered in a broader context the argument makes no real sense, as much scientific research, as well as some research from the disciplines of law, history and politics, do precisely that - and because good quality journalism does more than 'merely collecting and presenting facts', it also involves juxtaposing facts and theories to create new insights, exposing discrepancies and serving the citizenry. All of these characteristics fit with the definition of research given in the National Statement, which states, after giving a disclaimer that there is no generally agreed definition of research, that: "Research'... includes work of direct relevance to the needs of commerce, industry, and to the public and voluntary sectors; scholarship; the invention and generation of ideas, images, performances, artefacts including design, where these lead to new or substantially improved insights' (2007, p. 7).

In 2006, Stephen Lamble (2006) presented a compelling case for recognising that journalism has a proud pedigree, as research methodologies go, and that it can and should be considered a valid means to research topics other than itself. Early in his piece he wrote: 
One of the most significant problems in journalism education today, is its perceived lack of a legitimate academic methodology. Yet the simple, logical fact is that journalism must have a methodology because journalism is, journalism happens. It is taught and learned, sold and consumed.

He goes on to cite other writers who have, over decades past, made the call for journalism academics to step up and claim their rightful place as academics skilled in the use of a legitimate and valuable research methodology. These include US journalism historian Frank Luther Mott who claimed: 'The idea that a doctoral dissertation must be dull, sesquipedalian, and so recondite that it requires translation into good English to be comprehensible to Tom, Dick or Harry, is a superstition of which no journalist should be guilty. We [journalists] should not renounce our birthright, which is fresh and effective English, for the pedant's mess of pottage' (Mott in Nafziger \& Wilkerson, 1949, p. 129, cited by Lamble, 2006) and Betty Medsger who wrote: 'The language used to describe journalism needs to go beyond the language of craft and trade and embrace some of the best language of the university. Not to do so may perpetuate a false modesty that has been harmful to journalism within the university' (1996, cited in Lamble, 2006).

He then proceeded to summarise several other writers who have defined and described the methodology of journalism; covering its roots in ancient Greece, the insights of Rudyard Kipling, and journalism's longstanding links with the disciplines of history and law. These descriptions collectively provide a functional working definition of the methodology of the discipline-which he described as 'a methodology that although unrecognised and multifaceted, must logically exist'. Lamble portrays journalism as a bag of tools in the way that ethnography is a bag of tools as opposed to being a genre of artifacts that can be studied. The tools in the journalism methodology kit include a go-to set of questions, a network based participant recruitment strategy, a fluid and opportunistic style of research planning that enables stumbled upon details to be incorporated into a project, a built-in attitude of skepticism and an industry code that prohibits certain behaviours. Lamble (2006) concluded his paper with a call to action, saying:

Another aim of this article was to convince journalism educators that it is in our own collective interests to demonstrate to the rest of academe, to our students, to industry and society generally that our discipline, 
journalism, has at least as strong and proud an academic pedigree as the closely related and generally respected disciplines of history and law.

\section{Most effective strategies}

It now seems that the most effective way for journalism academics to achieve this is to start using the methodology of journalism to produce pieces of research-quality work and seek to get them recognised as research. To facilitate this, the new journal Research Journalism was established in early 2010 to provide a peer-review mechanism and a vehicle for publication of these pieces. Complicating the process, however, is the old chestnut of how to get research proposals involving journalism as a methodology approved by HRECs. This prompted Ian Richards to open a discussion about journalism and HRECs in a paper presented at the 2009 Journalism Educators Association Australia annual conference and published in early 2010.

His article plots the history of the relationship between journalism and HRECs and touches on definitions of research. Specifically he says that for a number of reasons journalism projects undertaken by academics are now more likely to fall under the definition of research and to be subject to institutional ethics requirements. He goes further and adds that this development undermines the position adopted by many journalism academics that research leading to publication in the news media should be exempt on the basis that 'the imposition of ethics requirements on research for media publication is a form of censorship which interferes with the ability of journalists to carry out their traditional role' (Richards, 2010, p. 41). 'Censorship' is a powerful word that seems apt in the university context, as anecdotal evidence suggests that very little journalism work is being approved HRECs. Gathering data on this is the aim of research planned for 2011. The risk of the HREC process being perverted into 'mere "rubber stamping" by the researcher's colleagues or a mask for disciplinary censorship' was raised by Cordner and Thomson (2007) who pointed out that s.5 of the revised National Statement gives HRECs advice on how to minimise those risks, but the extent to which that advice is taken is unknown. In discussing censorship, Errington and Miragliotta (2007) raised the preemptive buckle, which in some workplaces sees journalists not told to tow a particular line towing it anyway, because they are seeking to impress, or not aggravate, their employers. It may be that while the HREC system was not designed with the intention of censoring university-based 
journalists that the effect is, none the less, that a group of academics who could be using a time-tested methodology to do socially useful work are being silenced by workplace politics.

This is not to say that the HREC system is unworkable for journalism. As Thomson (personal communication, 2010) said: 'Ethics checking is a legitimate institutional requirement' and 'a main aim of the committees that drafted the National Statement in 1999 and, reviewed it in 2007 were careful to leave it open enough to allow as much beneficent research as possible.' In addition,

Despite the flexibility now built into the National Statement, in many cases journalism academics still report having problems with HRECs. Richards (2010) reported this and, as a statement, it elicits sighs of agreement from gatherings of journalism academics. There are many reasons why this could be happening: It could be that journalism academics are not submitting applications to HRECs; that they are not asking for exemptions from the usual requirements for demonstrating informed consent; that they are not asking for exemptions in ways that HRECs understand and can approve; or that HRECs are choosing to interpret the National Statement more cautiously and rigidly than they need to.

Asked about this, Thomson (personal communication, 2010) said that it appears to him that HRECs over recent years have been becoming increasingly risk averse, and this is manifesting as a mechanistic response to applications. Stressing that he was expressing his own opinion and not the committee's view, he said: 'It's become about ticking the boxes and saying "no" if possible, not looking at ways that the researcher can proceed and being creative about how the intentions of the National Statement can be met while still allowing the project to go ahead.' Asked why this was happening, he added that within many HRECs there was a fear of being wrong, or making mistakes and that included fear of making the error of approving research that is poorly designed. He said: 'This occurs because HREC members have rare opportunities to see reviews by other committees and their anxiety plays into the assumption that getting it wrong exposes them as committee members to consequences.' He went on to point out that this is an erroneous fear because s.5.1.9 of the National Statement states that institutions should provide an assurance of legal protection to all those involved in ethical review of research for liabilities that may arise in the course of bona fide conduct of their duties in this capacity. In December 2009 the NHMRC updated its advice to HRECs and universities on 
indemnity of HREC members in the context of the HoMER (Harmonisation of Multi-centre Research) initiative via the publication of online questions and answers. Although the answers recognize the theoretical possibility of claims, they indicate that the likelihood is very low (NHMRC, 2009).

Commenting on the 2007 review, Thomson (personal communication, 2010) recalled the lengthy discussions that gave rise to the line 2.2.1 which states: The guiding principle for researchers is that a person's decision to participate in research is to be voluntary, and based on sufficient information and adequate understanding of both the proposed research and the implications of participation in it. He said the conversation was protracted because they wanted the clause to be able to be 'flexibly interpreted'. But he also noted that HRECs did not always take up the options for flexibility about ways to get consent. While the National Statement, in clauses 2.2.4, 2.2.5 and elsewhere, says things like 'The process of communicating information to participants and seeking their consent should not be merely a matter of satisfying a formal requirement' and 'consent may be expressed orally, in writing or by some other means depending on the nature, complexity and level of risk of the research; and the participant's personal and cultural circumstances', many HREC members and researchers believe that signed consent letters are a compulsory part of university human research. Thomson added: 'The National Statement is a little bit freer than many HRECs think they are capable of being.'

\section{Climate of toleration}

One of the strangest things about the current situation is that it is tolerated. Journalism academics are like slow boiled frogs in their acceptance of the discrimination against and/or limitations placed on their practice by the bureaucratic processes of some HREC committees. Instead of arguing, as we would do if limitations such as these were suddenly imposed on commercial media, journalism academics have, over time, developed a series of work-arounds, compromises and in some cases solutions negotiated at the university HREC level. Workarounds include the inclusion of lines in in-house ethics policies that describe journalism as 'Not "research" as such' and therefore exempt it (University of Technology, Sydney [UTS], 2010); compromises include doing academic work that is not journalism such as writing commentary/pedagogy/cultural studies pieces that can be done slowly and/ or without human participants; and solutions include progressive agreements in some universities that allow the fast tracking of low risk projects and 
approvals in tune with the spirit of the amendments made to the National Statement in the 2007 review. These institutions may be taking advantage of the clauses built in to the National Statement indicated in this line from page 8: 'Research involving no more than low risk may be reviewed under other processes described in paragraphs 5.1.18 to 5.1.21. Institutions may also determine that some human research is exempt from ethical review (see paragraphs 5.1.22 and 5.1.23).' There is scope for further research on how these solutions were achieved and whether they can be replicated in universities where journalism academics face more difficulty.

In 2006, Bacon wrote 'to build journalism as a professional practice form of research in a university is a challenging long term and necessarily collaborative project'. Since then a number of initiatives have been taken including the lobbying that has seen portfolios of journalism rendered admissible into the ERA process and recent submissions by Mark Pearson and Julie Posetti on the proposed new federal shield laws arguing that academic journalists and students should be included. Collaborative work on providing support and guidance on ethics approvals is hindered however by the fact that, in addition to all working from the National Statement, each university has an in-house ethics policy, which dictates what researchers must do to gain the committees' stamp of approval. These differ significantly with some, including lines exempting journalism academics from always seeking prior written consent for interviews, while others take a harder line and cull away the sections of the National Statement that allow for exemptions from the requirement to acquire signed consent prior to data collection. More confusing still is the fact that it is often not clear at the outset how much detail ethics committees require in applications. In addition, many HRECs force applications through online approval systems that don't allow scope for real-time conversations between applicants and committee members. This leaves journalism academics across Australia with differing degrees of latitude and almost no one to talk to find ways through the maze of ethics approval.

Projects that are approved in some universities are rejected in others, often leaving the researchers wondering what they are doing wrong that journalism academics in other institutions are doing right. The downside of these bureaucratic refusals is clearly reduction of the productivity of journalism academics, diminishing their contribution to the Fourth Estate and reducing their universities' research output tallies. 
Further muddying the field, are the varying levels of compliance with university ethics policies that have become normal in various schools and faculties within universities. While some clusters of academics follow their HREC policies to the letter, many do not. For example, in a paper about the management of research ethics in academic business publications, Greenwood (2010) reported on the results of a survey and interviews with journal editors that found that requirement for ethics approvals were rare and that the editors had mixed views about the need for ethics approvals, with some saying that such a requirement would be counterproductive, both for the needs of the journal and for the ethical integrity of the research itself.

This raises the issue of the shadow that falls between the sweeping statements made by universities about all research being subject to ethics approval and the reality that some make no attempt to check whether the research being published by their academics has been assessed or approved by their HRECs. There is a chance that advancing digital tracking systems will close these loopholes in the near future, but for now it appears that in the humanities no negative consequences arise from not doing the bureaucratic process of getting HREC approval for low risk research, other than reinforcement of the misconception that journalism is not 'proper research'.

Confusion also arises when journalism academics are part time employed or do freelance work on the side, and they are faced with the option of considering it to be either university work or not. Thomson (personal communication 2010) acknowledged that this was an awkward situation to which no clear answers were available.

Another major reason behind university journalists' aversion to HRECs is the awkwardness of the fit between the way journalism work usually proceeds, (with ideas being sparked by initial conversations that may later become part of the project) and the 'planning before execution model' that is hardwired into the HREC process. This is problematic because the HREC process does not allow for retrospective approval of a project once data gathering (the first journalistic interview) has taken place. This can be taken to mean that if the initial conversations/interviews that sparked the research are to be used or quoted in the resulting article then the interviews have to be re-done after ethics approval is granted, but this is not always a sensible or logical way of working. Asked about this problem, Thomson (personal communication, 2010) said: 
The notion of prior approval is a key conceptual premise of the system, which is based on medical research that can be planned in advance. With medical research prior approval is a necessary precondition that doesn't work sensibly in the context of the humanities. To re-conceptualize this premise it is necessary to question the notion that you can pinpoint the time when research starts. If you can do that then requiring prior approval makes sense. If you can't, as you often can't in journalism and the humanities then it doesn't make sense. What this means from an HREC perspective is that they say 'at the moment that you have an idea about an article you'd like write come and talk to us'.

This may mean journalism academics develop routines of submitting applications each time a possible story idea presents itself, rather than waiting until the research is underway and the idea is confirmed to 'have legs', even though this may mean committees need to review scores of applications for articles that don't eventuate. Thomson continued, saying:

The real point that they should be looking at is that the research is done well, not retrospectivity, so if you have already done an interview prior to applying then it is not difficult to think of ways that the HREC committee could look at that to assess the research, they could approve transcripts, or require that participants be able to approve transcripts, there are opportunities for committees and researchers to work together to ensure that the intention of the National Statement is followed, while not requiring interviews to be re-done, or the use of signed consent forms or pre-vetted questions, in cases where that would be inappropriate for the research in question. (Personal communication, 2010).

The process of gaining ethics approval to interview Thomson for the purpose of writing this paper was, however, a case study in difficulty. It took ten weeks and involved four resubmissions of my application. At no stage was I proposing to do anything unethical. My proposal sought permission to interview a professional person with relevant expertise who had already offered to be involved. The process was educational, however, and my final, successful, application was far briefer than the earlier versions. The process also has sparked conversations with colleagues in my own and other universities that will, hopefully, result in faster approval for my next project and in the creation of resources that other journalism academics can turn to for help with their own ethics applications. 
Working with HRECs is challenging not only because of the time it takes to fill in online forms and to craft answers to often obscure and repetitive questions. It is challenging because there is a risk of rejection and failure, that requires either that a good story be dropped for bureaucratic reasons or engagement in negotiation with the committee. It is worth noting that dropping a story for bureaucratic reasons runs against the grain of university journalists who take to heart industry codes that discourage allowing anything corporate, financial or personal to undermine the quest for accuracy, fairness and independence (MEAA, 2010).

The spectre of HREC rejection and the perception that it may be stigmatising should not be underestimated. Bacon (2006) raised the issue that journalism academics had reported feeling undervalued within their faculties. While she said those days are fading, it is still fair to wonder who wants to challenge something as beatifically named as an Ethics Committee. Seeking but failing to get approval can open up the discipline to old insults about journalism not being 'proper academia', and journalism academics may be concerned that they as individuals will be perceived as unethical or as trying to get away with something that others are forced to do. The other risks are that individuals may simply not have time to engage in lengthy negotiations or that in trying to change the status quo they could be perceived as trouble makers-making work where others perceive no real problem. From a cultural studies perspective this can be framed as a masculine/dominant use of dismissive formulas to silence voices of dissent by calling them subjective/irrational.

Attempts to get journalism research approved may meet with institutional prejudice that counteracts critique of the status quo with 'get over it/it's a personal problem/you must be incompetent or not coping' response. To tackle this, journalism academics need to develop a body of work that firmly identifies the contradiction between the ideal of an ethics approval system that improves the quality of Fourth Estate research by journalism academics, with the reality of current system that hinders ethical research for reasons inconsistent with the intent of the authors of the National Statement. This work can use concrete examples to demonstrate the lived contradictions within the current system and to commence discussions about pragmatic work-arounds and solutions giving the pros and cons of action and inaction on the part of institutions.

Another challenge facing journalism academics lobbying for less contested passage through HREC processes is overcoming negative stereotypes that 
portray journalism as inherently unethical. Journalism projects undertaken by academics should be of the highest ethical standards, and peer review can provide a check on this. Sadly though, tabloid and shallow commercial infotainment, which can be in breach of both industry codes and the law, are often foremost in the minds of academics from other disciplines when they are asked to consider the ethics of research journalism-despite the requirement in the National Statement that HRECs 'have sufficient expertise in the area of research it has to review' (Cordner \& Thomson, 2007, p. 39). When this happens, reference to recent discussions about the shift away from journalism that styles itself as omniscient, towards journalism that articulates commitment to specific ethical positions (Heyward, 2005; Ward 2010) can make it easier for journalism academics to articulate rationales for journalism that make sense in the context of ethics applications.

Ward (2010) and Heyward (2005) claim that the omniscient detached journalist is no longer credible, as we all know everyone has a position and so journalists should publicly adopt some broad egalitarian positions and write from them. Ward goes as far as giving a suggested list that would serve as a global journalism ethics, including opposing abuses of human rights and manipulation of information by special interest groups. In addition to working in favour of good causes, being upfront about supporting these positions could also help to counter the negative stereotypes that all or most journalists are ruthless, selfish or gullible. It can also be argued that as opposed to hindering that by supporting the growth and development of a body of peer-reviewed research journalism, HRECs would be contributing to the establishment of new industry standards of ethical integrity for journalism.

Cordner and Thomson (2007) highlight sections of the National Statement that allow HRECs to make changes to the usual processes and to introduce supplementary or replacement guidelines that may be relevant to specific disciplines. These could allow an industry code, such as the MEAA code of ethics, to play a part in managing the behaviour of academic journalists. While this may seem like a desirable loophole that could circumvent red tape, Lindorff (2010) pointed out that it is important to remember that the intention behind the ethics approval process is the improvement of research by prompting researchers to seriously consider the benefits and potential harms that may arise from their work. 


\section{Conclusion}

In conclusion, this article has argued that it is not impossible to get journalism projects through HREC committees but that some problems arise in some universities, because of unfamiliarity or excessive rigidity on the part of either journalism academics or HREC members or both. It has also proposed three courses of action open to journalism academics keen to change the status quo and to make it easier to get ethical journalism research approved by HRECs in a way that is not unduly time consuming and that does not compromise the quality of the research.

The first of these involved gathering more information about the extent of the problem, and research planned for 2011 will seek to find out how many journalism as research projects are being passed and rejected by HRECs in Australian universities. The second strategy is to employ the methods and conceptual frameworks of cultural studies to describe the lived contradiction between the ideal of an effective HREC system and the current reality, and to academically explore possible solutions. The third suggestion is for journalism academics to start to increase their use of the system as it stands in order to build a body of evidence about the difficulties inherent in it or perhaps to become more adept at using it or to, through dialogue, familiarise their HRECs with the ethical underpinnings of the methodology of journalism and the clauses built in to the National Statement to allow Fourth Estate work to be approved. An important second stage of this strategy is to work collaboratively with other journalism academics and to contribute to a discipline-wide resolution of the problems. While the aim is to simply remove the problems that currently make HREC approvals difficult and time consuming for many journalism academics, the path to attaining that carefree state may involve some hardship, and require journalism academics to become the squeaky wheels in the system, motivating change by clearly articulating the shortfalls in the status quo.

\section{References}

Bacon, W, (2006). Journalism as research? Australian Journalism Review, 28(2), pp. $147-157$

Bromley, M. (2006). How good is journalism research? Australian Journalism Review, 28(1), pp. 211-118.

Cordner, C. \& Thomson, C. (2007). No need to go! Workplace studies and the revised

National Statement. Monash Bioethics Review, 26(3), pp. 37-48. 
Davies. N. (2008). Flat earth news: An award-winning reporter exposes falsehood, distortion and propaganda in the global media. London: Chatto and Windus.

Davies, K. (2010). Journalism as research within the framework of academic ethics. Paper presented to the Australian Association of Professional and Applied Ethics 17th Annual Conference, University of Sydney, 15-17 June 2010.

Errington, W. \& Miragliotta, N. (2007). Media \& politics: An introduction. Melbourne: OUP.

Evans, C. \& Carr K. (October 26, 2010). Joint media release: University compacts to reward high performance. Retrieved on November 22, 2010, from www.deewr. gov.au/ministers/evans/media/releases/pages/article_101026_140947.aspx

Greenwood, M. (2010). Management of research ethics in academic business publications. Paper presented to the Australian Association of Professional and Applied Ethics 17th Annual Conference, University of Sydney, 15-17 June 2010.

Heyward, A. (Oct 19, 2005). The era of omniscience is over. Published on PressThink. org. Retrieved on 22 November 2010, from: archive.pressthink.org/2005/10/19/ hwd_era.html

Lamble, S. (2004). Documenting the methodology of journalism. Australian Journalism Review, 26(1), pp. 85-106.

Lindorff, M. (2010). Ethics, ethical human research and human research ethics committees. Australian Universities'Review, 52(1), pp. 51-59.

Media Entertainment and Arts Alliance. (1999). Journalists' Code of Ethics.

National Health and Medical Research Council (NHMRC), Australian Research Council \& Australian Vice-Chancellors' Committee. (2007). National Statement on Ethical Conduct in Research Involving Humans. Canberra: Commonwealth of Australia.

National Health and Medical Research Council (NHMRC) (2009). Indemnity and Insurance $Q \& A s$. Retrieved on 22 November 2010, from www.nhmrc.gov.au/ health_ethics/homer/qa/qa_indemnity_insurance.htm\#1

Richards, I. (2010). Uneasy bedfellows: Ethics committees and journalism research. Australian Journalism Review, 31(2), pp. 35-46.

Rosen, J. (April 8, 2008). Newspapers \& the net: Where's the business model, people? Published on The Britannica Blog. Retrieved on 22 November 2010, from www.britannica. com/blogs/2008/04/newspapers-the-net-wheres-the-business-model-people/

Tiffen, R. (2009). Australian Journalism. Journalism. 10(3), pp. 384-386.

University of Technology, Sydney (1999). Ethical conduct of research-Academic and support staff policy. Retrieved on 30 June 2010, from www.gsu.uts.edu.au/ policies/researchethicpol.html

Ward, S. (2010). Global journalism ethics. Montreal: McGill-Queens University Press. 
Dr Kayt Davies is a senior lecturer in journalism at Edith Cowan University. Initially trained as a cadet journalist in business news, she has worked for The West Australian, Visnews (London), and edited communitynewspapers and magazines. She has a BA (psych) honours, an M.Phil in English and Comparative Literature and her PhD was an ethnographic study of women's magazine editors. She is editor-in-chief of 3rd Degree, ECU's online student publication, and in 2009 she was awarded a Vice-Chancellor's citation and an Australian Learning and Teaching Council Citation for outstanding contributions to student learning.

k.davies@ecu.edu.au

\section{//Annual \\ conference}

$1 \& 2$ December 2011

City Campus, Wintec, Hamilton, Waikato

Convenor: Charles Riddle

Ph: +64 78348800

Email: Charles.riddle@wintec.ac.nz
Abstracts: Jim Tully

Ph: +64 33642881

Email: jim.tully@canterbury.ac.nz
Registration: Jeremy Smith

Ph: +64 78348800

Email: Jeremy.smith@wintec.ac.nz 